\title{
Some Bits and Pieces of the Genus Nocardia: N. carnea, N. vaccinii, $N$. transvalensis, $N$. orientalis and $N$. aerocolonigenes
}

\author{
By R. E. GORDON, S. K. MISHRA AND D. A. BARNETT \\ Waksman Institute of Microbiology, Rutgers, The State University of New Jersey, \\ P.O. Box 759, Piscataway, New Jersey 08854, U.S.A.
}

(Received 22 May 1978)

\begin{abstract}
Since 1951 when our taxonomic study of the genus Nocardia began, only eight strains of $N$. carnea (Rossi-Doria) Castellani \& Chalmers, four strains of $N$. vaccinii Demaree \& Smith, five of $N$. transvalensis Pijper \& Pullinger, 21 of $N$. orientalis (Pittenger \& Brigham) Pridham and 14 of $N$. aerocolonigenes (Shinobu \& Kawato) Pridham have been found. These five groups of strains are described and are compared with strains of nine accepted species of Nocardia. With the possible exception of $N$. orientalis, more strains of these five taxa must be assembled and examined to establish the reliability of our descriptions and identifications.
\end{abstract}

\section{INTRODUCTION}

An ideal description of a microbial species is based on many strains, including freshly isolated strains, old stock strains and strains from different sources. In a collection of micro-organisms, however, some strains that appear to be taxonomically distinct accumulate only in very small numbers. Our collection of nocardiae, begun in 1951 as an outgrowth of several collections including the one initiated by S. A. Waksman in 1914, has its quota of these oddments. Because so few of these strains are available, descriptions of their species must remain tentative. These small aggregates of strains are, nevertheless, part of the genus Nocardia, and a few are described here and compared with strains of nine recognized species. We are well aware that when more strains can be examined some properties that now appear to be distinctive may be reduced to variable properties and that some of these aggregates of strains may prove to belong to currently accepted species.

\section{METHODS}

Strains. Our strains of the five aggregates are listed in Table 1 with their respective histories and, when known, their sources of isolation. Strains of nine species of Nocardia, included for comparative purposes, were representative strains of $N$. amarae and $N$. hirsuta (listed in Table 1) and the strains of seven other species used by Gordon et al. (1974).

Observations. Morphological, physiological and chromatographic examinations of the strains were made according to the methods described by Gordon et al. (1974) and Gordon \& Barnett (1977). In addition, cellobiose, glycerol and melezitose were tested for acid formation. All cultures that did not produce acid from the various carbohydrates after 4 weeks incubation at $28^{\circ} \mathrm{C}$ were incubated and re-examined at 8 weeks. For a representative number of strains of each of the 14 taxa, the method of Hecht \& Causey (1976) was used for the determination of lipid characteristic of Nocardia spp., type A (LCN-A). 


\section{Table 1. Designation and source of strains}

(a) Strains identified as Nocardia carnea (Rossi-Doria 1891) Castellani \& Chalmers 1913

ATCC 6847 IMRU 134

IMRU 1406 IMRU 1642

IMRU 1674 IMRU 1684

IMRU 3419 IMRU 3809

ATCC 11092*

JMRU 1072 , 1074

IMRU 3500*

NCTC 2392*

IMRU 1222

IMRU 1301

IMRU 1583

IMRU 3426*
N. carnea; R. St. John-Brooks, NCTC (3527); V. Puntoni

Streptomyces sp.; J. W. Brandsburg, Natl Insts of Health, Bethesda, Md. (в2898, from pleural fluid)

N. convoluta; M. Goodfellow, Univ. of Leicester (N95); A. Gonzalez Ochoa (98)

Unidentified isolation; L. E. Vázquez, Puerto Rico Medical Center, San Juan, Puerto Rico (Cm624, eye of a patient)

Nocardia sp.; K. P. Schaal, Univ. zu Köln (N14)

Unidentified isolation; J. B. Fischer, Ontario Ministry of Health, Toronto (FT55-75, from pleural fluid)

N. carnea; ATCC 6847 ; NCTC 3527 ; V. Puntoni

N. carnea; Lederle Laboratories, Pearl River, N.Y.; ATcc 6847

(b) Strains identified as Nocardia vaccinii Demaree \& Smith 1952

N. vaccinii; N. R. Smith, U.S. Dept of Agr. (BG19, from blueberry gall)

Streptomyces spp.; J. B. Routien, Chas. Pfizer \& Co., Brooklyn, N.Y. (AR368,

$38366-20$ and AP9545, 50392-017)

N. vaccinii; J. B. Demaree, U.S. Dept of Agr. (BG19, from blueberry gall)

(c) Strains identified as Nocardia transvalensis Pijper \& Pullinger 1927

N. transvalensis; S. T. Cowan, NCTC (2392); A. Pijper (16)

Unidentified isolation; F. Mariat, Inst. Pasteur (945, from a mycetoma)

N. brasiliensis; M. Moore, Homer G. Phillips Hospital, St Louis, Mo. (1, from a mycetoma)

N. asteroides; M. Magnusson, Statens Seruminstitut, Copenhagen (667); F. Mariat

(IP766 Cameroun, from a mycetoma)

N. transvalensis; ATCC 6865 ; NCTC 2392

(d) Strains identified as Nocardia orientalis (Pittenger \& Brigham 1956) Pridham 1970

ISP $5040^{*}$

IMRU 1107

IMRU 1148,

1149

IMRU 1311

IMRU 1389,

1390 ,

1409

IMRU 1591,

1592

IMRU 1600

IMRU 1601

IMRU 1627 ,

1628

IMRU 1631 1633

IMRU 1637 , 1640

IMRU 1644

IMRU 1671
Streptomyces orientalis; International Streptomyces Project (5040); R. C. Pittinger (M43-05865)

Streptomyces sp.; J. M. Mihm, Rutgers Univ. (from rotting egg plant)

Streptomyces spp.; T. H. Stoudt, Merck \& Co., Rahway, N.J. (C of 'Red' group and $\mathrm{D}$ of 'Red' group)

Nocardia-Streptomyces group; M. P. Lechevalier, Rutgers Univ. (F719, from a clinical specimen)

N. brasiliensis; J. Scharfen, Inst. of Epidemiology and Microbiology, Prague (AK-16/65, W-113/66 and AK-4348)

Micropolyspora spp.; L. K. Georg, Center for Disease Control, Atlanta, Ga. (w2100 and w2101, from Sudan soil)

N. orientalis; T. G. Pridham, U.S. Dept of Agr., Peoria, Ill. (NRRL B-3891)

Micropolyspora sp.; L. K. Georg, Center for Disease Control, Atlanta, Ga. (w2156, from Sudan soil)

N. orientalis; T. G. Pridham, U.S. Dept of Agr., Peoria, Ill. (NRRL B-2451 and B-2452)

N. orientalis; C. E. Higgens, Eli Lilly \& Co., Indianapolis, Ind. (A25284, A37317 and M48-E2570)

Nocardia spp.; M. P. Lechevalier, Rutgers Univ. (5-8, from soil containing 9400 p.p.m. $\mathrm{Zn}$, and 11-14, from soil with low $\mathrm{Zn}$ content)

N. orientalis; G. Carroll, Center for Disease Control, Atlanta, Ga. (w2684, from spinal fluid)

Unidentified isolation; M. P. Lechevalier, Rutgers Univ. (26-75, from soil)

(e) Strains identified as Nocardia aerocolonigenes (Shinobu \& Kawato 1960) Pridham 1970

ISP 5034*

IMRU 550

IMRU 983

IMRU 1106

IMRU 1432

IMRU 1546,

1566

IMRU 1589

IMRU 1593 ,

1594 ,

1599 ,

IMRU 1663 , 1667 , 1668
Streptomyces aerocolonigenes; International Streptomyces Project (5034); R. Shinobu (701)

Nocardia sp.; E. N. Azarowicz, Univ. of California, Los Angeles (30, from California soil)

Nocardia sp.; M. P. Lechevalier, Rutgers Univ. [1a(3), from soil]

Streptomyces sp.; J. M. Mihm, Rutgers Univ. (from soil)

Nocardia sp.; M. P. Lechevalier, Rutgers Univ. (T3)

Unidentified isolations; T. G. Pridham, U.S. Dept of Agr., Peoria, Ill. (NRRL B-3274, from desert soil, and B-11267, from garden soil)

N. brasiliensis; L. K. Georg, Center for Disease Control, Atlanta, Ga. (w1894, from spinal fluid)

Unidentified isolations; L. K. Georg, Center for Disease Control, Atlanta, Ga. (w2104, w2105 and w2158, from Sudan soil)

Unidentified isolations; M. P. Lechevalier, Rutgers Univ. (26-39 and 26-67, from soil heavily polluted with $\mathrm{Zn}$ and $\mathrm{Cd}$, and $26-69$, from soil) 


\section{Table 1. Designation and source of strains-continued}

(f) Strains examined of Nocardia amarae Lechevalier \& Lechevalier 1974

IMRU 15291533

IMRU 15351539

IMRU 1604 1606

IMRU 3960*

Nocardia amarae; M. P. Lechevalier, Rutgers Univ. (Se3, Se51, Se64, Se85 and Se87)

Nocardia amarae; M. P. Lechevalier, Rutgers Univ. (Se107, Sel10, Se111, Sel17 and Sel02)

Unidentified isolations; V. D'Aco, 12D Fletcher Rd, Monsey, N.Y. (9c, 10a and 10b, from activated sludge)

Nocardia amarae; M. P. Lechevalier, Rutgers Univ. (Se6)

(g) Strains examined of Nocardia hirsuta (Saccharopolyspora hirsuta Lacey \& Goodfellow 1975)

IMRU 1437 1439

IMRU 1461 1463

IMRU 1475 1476

IMRU 1547 1557 IMRU 1558* 1562
Nocardia spp.; J. Lacey, Rothamsted Experimental Station, England (AI53, A197 and $\mathrm{A} 216$ )

Nocardia spp.; J. Lacey, Rothamsted Experimental Station, England (A205, A206 and $\mathrm{A} 770$ )

Nocardia spp.; J. Lacey, Rothamsted Experimental Station, England (A185 and A195)

Nocardia spp.; J. Lacey, Rothamsted Experimental Station, England (A1132, A1133, A1134, A1135, Al136, Al137, Al138, Al139, Al140, Al141 and Al142)

Nocardia spp.; J. Lacey, Rothamsted Experimental Station, England (A1143, Al144, A1145, A1146 and A1147)

* Nomenclatural type strain.

ATCC, American Type Culture Collection; IMRU, Waksman Institute of Microbiology, Rutgers University; NCTC, National Collection of Type Cultures; ISP, International Streptomyces Project.

\section{RESULTS}

\section{Nocardia carnea}

Macroscopically the growth of cultures of $N$. carnea at 1 to 2 weeks on yeast dextrose agar was abundant, cream- or peach-coloured and moderately or thickly covered with whitish aerial hyphae. They closely resembled cultures of some strains of $N$. asteroides. Cultures of ATCC 6847 , obtained from the NCTC in 1938, still formed an abundance of aerial hyphae. Microscopically the colonies were loosely filamentous, and the aerial hyphae of two of the eight cultures (ATCC 6847 and IMRU 3809) segmented into conidia. Smears of cultures grown on glycerol agar showed coccoid forms, rods and/or filaments. Cultures of two of the eight strains were acid-fast.

The physiological properties of strains of $N$. carnea were very like those of strains of $N$. asteroides (Tables 2 and 3). Positive characteristics of strains of $N$. carnea (positive for 85 to $100 \%$ of the strains) were: resistance to lysozyme and rifampin; hydrolysis of aesculin; acid formation from glucose, glycerol, mannitol, sorbitol and trehalose; utilization of succinate; reduction of nitrate to nitrite; and survival at $50{ }^{\circ} \mathrm{C}$ for $8 \mathrm{~h}$. Negative characteristics (positive for 0 to $14 \%$ of the strains) were: decomposition of adenine, casein, hypoxanthine, tyrosine, urea and xanthine; hydrolysis of hippurate; production of acid from adonitol, arabinose, cellobiose, erythritol, lactose, maltose, melezitose, melibiose, methyl $\alpha$-glucoside, raffinose, rhamnose and xylose; and utilization of benzoate, mucate and tartrate. Only the inability to form urease and the ability to produce acid from mannitol and sorbitol separated strains of $N$. carnea from typical strains of $N$. asteroides.

\section{Nocardia vaccinii}

On yeast dextrose agar, the growth of cultures of $N$. vaccinii was cream- or peach-coloured and moderately covered with white aerial hyphae. When examined microscopically, colonies of the four strains were loosely filamentous and showed short or long, branching aerial hyphae. Conidia were formed by the aerial hyphae of one strain (IMRU 1072). Cultures grown on glycerol agar were composed of partially acid-fast rods and filaments.

Positive physiological reactions of the strains were: decomposition of urea; resistance to lysozyme; hydrolysis of aesculin and starch; formation of acid from arabinose, glucose, glycerol and mannitol; utilization of citrate, mucate and succinate; reduction of nitrate to 
Table 2. Some physiological properties of nine species and five aggregates of Nocardia

Results indicate the percentage frequency of positive characters.

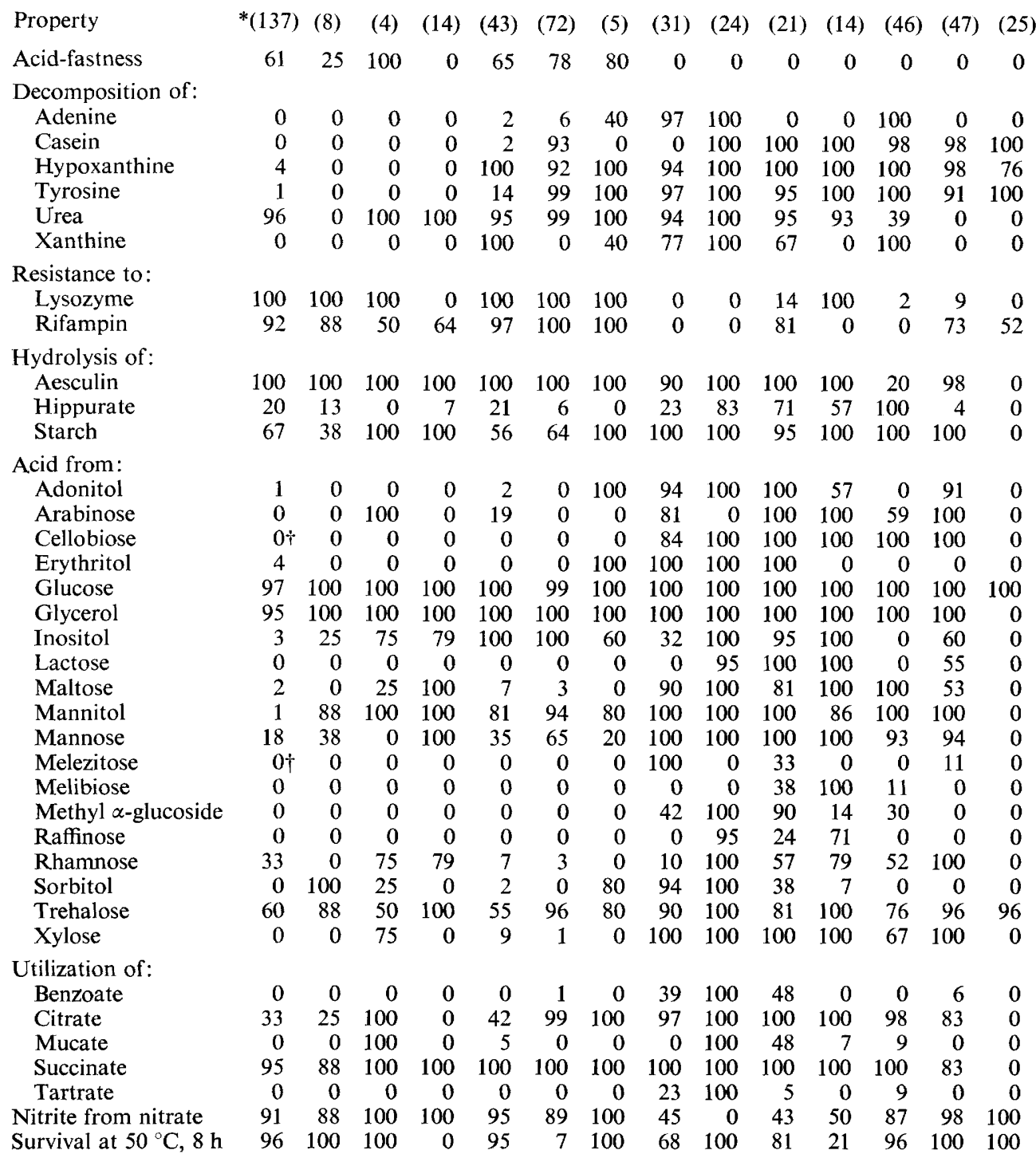

* Numbers in parentheses indicate the number of strains examined.

$\dagger$ One hundred strains examined. 
Table 3. Some physiological properties of typical strains of 14 taxa of Nocardia

Property

Acid-fastness

Decomposition of:

Adenine

Casein

Hypoxanthine

Tyrosine

Urea

Xanthine

Resistance to:

Lysozyme

Rifampin

Hydrolysis of:

Aesculin

Hippurate

Starch

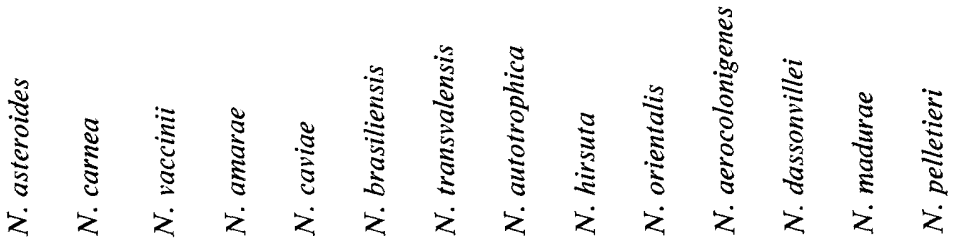

Acid from:

Adonitol

Arabinose

Cellobiose

Erythritol

Glucose

Glycerol

Inositol

Lactose

Maltose

Mannitol

Mannose

Melezitose

Melibiose

Methyl $\alpha$-glucoside

Raffinose

Rhamnose

Sorbitol

Trehalose

Xylose

Utilization of:

Benzoate

Citrate

Mucate

Succinate

Tartrate

Nitrite from nitrate

Survival at $50^{\circ} \mathrm{C}, 8 \mathrm{~h}$

$\begin{array}{llllllllllllll}- & - & - & - & - & - & \mathrm{v} & + & + & - & - & + & - & - \\ - & - & - & - & - & + & - & - & + & + & + & + & + & + \\ - & - & - & - & + & + & + & + & + & + & + & + & + & \mathrm{v} \\ - & - & - & - & - & + & + & + & + & + & + & + & + & + \\ + & - & + & + & + & + & + & + & + & + & + & v & - & - \\ - & - & - & - & + & - & \mathrm{v} & \mathrm{v} & + & \mathrm{v} & - & + & - & -\end{array}$

$\begin{array}{lllllllllllllll}+ & + & + & - & + & + & + & - & - & - & + & - & - & - \\ + & + & \mathrm{v} & \mathrm{v} & + & + & + & - & - & \mathrm{v} & - & - & \mathrm{v} & \mathrm{v}\end{array}$

$\begin{array}{llllllllllllll}+ & + & + & + & + & + & + & + & + & + & + & v & + & - \\ v & - & - & - & v & - & - & v & v & v & v & + & - & - \\ v & v & + & + & v & v & + & + & + & + & + & + & + & -\end{array}$

$\begin{array}{llllllllllllll}- & - & - & - & - & - & + & + & + & + & v & - & + & - \\ - & - & + & - & \mathrm{v} & - & - & \mathrm{v} & - & + & + & \mathrm{v} & + & - \\ - & - & - & - & - & - & - & \mathrm{v} & + & + & + & + & + & - \\ - & - & - & - & - & - & + & + & + & + & - & - & - & - \\ + & + & + & + & + & + & + & + & + & + & + & + & + & + \\ + & + & + & + & + & + & + & + & + & + & + & + & + & - \\ - & \mathrm{v} & \mathrm{v} & \mathrm{v} & + & + & \mathrm{v} & \mathrm{v} & + & + & + & - & \mathrm{v} & - \\ - & - & - & - & - & - & - & - & + & + & + & - & \mathrm{v} & - \\ - & - & \mathrm{v} & + & - & - & - & + & + & \mathrm{v} & + & + & \mathrm{v} & - \\ - & + & + & + & \mathrm{v} & + & \mathrm{v} & + & + & + & + & + & + & - \\ \mathrm{v} & \mathrm{v} & - & + & \mathrm{v} & \mathrm{v} & \mathrm{v} & + & + & + & + & + & + & - \\ - & - & - & - & - & - & - & + & - & \mathrm{v} & - & - & - & - \\ - & - & - & - & - & - & - & - & - & \mathrm{v} & + & - & - & - \\ - & - & - & - & - & - & - & \mathrm{v} & + & + & - & \mathrm{v} & - & - \\ - & - & - & - & - & - & - & - & + & \mathrm{v} & \mathrm{v} & - & - & - \\ \mathrm{v} & - & \mathrm{v} & \mathrm{v} & - & - & - & - & + & \mathrm{v} & \mathrm{v} & \mathrm{v} & + & - \\ - & + & \mathrm{v} & - & - & - & \mathrm{v} & + & + & \mathrm{v} & - & - & - & - \\ \mathrm{v} & + & \mathrm{v} & + & \mathrm{v} & + & \mathrm{v} & + & + & \mathrm{v} & + & \mathrm{v} & + & + \\ - & - & \mathrm{v} & - & - & - & - & + & + & + & + & \mathrm{v} & + & -\end{array}$

,+ 85 to $100 \%$ of the strains positive;,- 0 to $14 \%$ of the strains positive; $v, 15$ to $84 \%$ of the strains positive. See Table 2 for numbers of strains examined. 
nitrite; and survival at $50{ }^{\circ} \mathrm{C}$ for $8 \mathrm{~h}$. The strains did not dissolve casein or the crystals of adenine, hypoxanthine, tyrosine or xanthine; hippurate was not hydrolysed; acid was not produced from adonitol, cellobiose, erythritol, lactose, mannose, melezitose, melibiose, methyl $\alpha$-glucoside or raffinose; and benzoate and tartrate were not used as sources of carbon (Tables 2 and 3). Only three properties (production of acid from arabinose and mannitol and the utilization of mucate) divided the four strains of $N$. vaccinii from strains of $N$. asteroides. The presence of urease, production of acid from arabinose and use of mucate distinguished strains of $N$. vaccinii from strains of $N$. carnea. Strains of $N$. vaccinii could be differentiated from strains of $N$. amarae by their acid-fastness, formation of acid from arabinose, failure to produce acid from mannose, resistance to lysozyme, utilization of citrate and mucate, and survival at $50{ }^{\circ} \mathrm{C}$ for $8 \mathrm{~h}$.

\section{Nocardia transvalensis}

The growth of cultures of $N$. transvalensis on yeast dextrose agar was abundant and thickly coated with whitish aerial hyphae. The pigments of the growth were cream or pale purple. The colonies of the five strains were loosely filamentous, and their aerial hyphae were long and branching. Conidia were not observed. The rods and filaments of four of the five strains grown on glycerol agar were 10 to $50 \%$ acid-fast. A culture of the fifth strain (IMRU 1583) exhibited only non-acid-fast coccoid bodies.

The distinctive pattern of characteristics of our five strains of $N$. transvalensis consisted of positive reactions on hypoxanthine, tyrosine, urea, lysozyme, rifampin, aesculin, starch, adonitol, erythritol, glucose, glycerol, citrate, succinate, nitrate and survival at $50{ }^{\circ} \mathrm{C}$ for $8 \mathrm{~h}$. Reactions were negative on casein, arabinose, cellobiose, lactose, maltose, melezitose, melibiose, methyl $\alpha$-glucoside, raffinose, rhamnose, xylose, hippurate, benzoate, mucate and tartrate (Tables 2 and 3). This pattern of reactions differentiated strains of $N$. transvalensis from typical strains of (i) $N$. caviae by their positive reactions on tyrosine, adonitol and erythritol, (ii) $N$. brasiliensis by their inability to decompose casein and by their ability to form acid from adonitol and erythritol and to survive at $50^{\circ} \mathrm{C}$ for $8 \mathrm{~h}$ and (iii) N. autotrophica by their resistance to lysozyme and rifampin and their negative reactions on cellobiose, maltose, melezitose and xylose.

\section{Nocardia orientalis}

Cultures of $N$. orientalis grew well on yeast dextrose agar. The growth, often wrinkled, was cream or peach in colour and sparsely or moderately covered with aerial hyphae. Microscopically colonies of the 21 strains were loosely filamentous, and colonies of 20 of the 21 strains produced long, straight, branching aerial hyphae, while those of one strain were short. The aerial hyphae of 11 strains formed conidia. Acid-fastness was not observed in any of the cultures.

Typical strains of $N$. orientalis decomposed casein, hypoxanthine, tyrosine and urea; they hydrolysed aesculin and starch; they formed acid from adonitol, arabinose, cellobiose, erythritol, glucose, glycerol, inositol, lactose, mannitol, mannose, methyl $\alpha$-glucoside and xylose; they utilized citrate and succinate; and survived at $50^{\circ} \mathrm{C}$ for $8 \mathrm{~h}$ (Tables 2 and 3). The strains were unable to dissolve the crystals of adenine. They were sensitive to lysozyme and did not use tartrate as a carbon source.

Strains of $N$. orientalis could be distinguished from strains of (i) $N$. al totrophica by their inability to decompose adenine and their positive reactions on casein and lactose, (ii) $N$. hirsuta by their negative action on adenine and tartrate and their ability to produce acid from arabinose and (iii) $N$. aerocolonigenes by their positive action on erythritol and methyl $\alpha$-glucoside and their sensitivity to lysozyme. 


\section{Nocardia aerocolonigenes}

Although cuitures of $N$. aerocolonigenes grew well on yeast dextrose agar, their viability was short compared with that of cultures of other Nocardia spp. The transfer of working stock cultures at intervals of no longer than 2 weeks is recommended as well as a substantial supply of lyophilized cultures.

The growth of the cultures on yeast dextrose agar was cream-coloured or pale orange. As reported by Shinobu \& Kawato (1960), the cultures quickly lost their ability to form aerial hyphae upon continued transfer. When first observed microscopically, the loosely filamentous colonies of eight of the 14 strains formed short or long, straight, branching aerial hyphae, and only one (IMRU 550) produced conidia. The cultures grown on glycerol agar were not acid-fast.

Positive physiological reactions of 85 to $100 \%$ of the strains were: decomposition of casein, hypoxanthine, tyrosine and urea; resistance to lysozyme; hydrolysis of aesculin and starch; production of acid from arabinose, cellobiose, glucose, glycerol, inositol, lactose, maltose, mannitol, mannose, melibiose, trehalose and xylose; and utilization of citrate and succinate. Negative characteristics (positive for 0 to $14 \%$ of the strains) were: decomposition of adenine and xanthine; resistance to rifampin; formation of acid from erythritol, melezitose, methyl $\alpha$-glucoside and sorbitol; and utilization of benzoate, mucate and tartrate. Among these properties, decomposition of adenine and xanthine, production of acid from inositol, lactose and melibiose and resistance to lysozyme differentiated strains of $N$. aerocolonigenes from strains of $N$. dassonvillei. Strains of $N$. aerocolonigenes were distinguished from those of $N$. madurae by the presence of urease, production of acid from melibiose and resistance to lysozyme.

\section{Chromatographic determinations}

Whole-cell hydrolysates of representative strains of $N$. carnea, $N$. vaccinii, $N$. transvalensis, $N$. orientalis and $N$. aerocolonigenes were examined for the presence of meso-diaminopimelic acid (meso-DAP), arabinose, galactose, glucose, madurose, mannose and lipid characteristic of Nocardia spp., type A (LCN-A). The results were compared with those of representative strains of nine species of nocardiae (Table 4). Representative strains of each taxon included the nomenclatural type or neotype strain, if designated. Under the conditions of our test, $90 \%$ of the strains of $N$. asteroides, $95 \%$ of the strains of $N$. caviae and $100 \%$ of those of the remaining 12 taxa contained meso-DAP. Hydrolysates of strains of N. carnea and $N$. transvalensis contained arabinose, galactose, glucose, mannose and LCN-A, but not madurose. Strains of $N$. vaccinii were positive for arabinose, galactose, glucose and LCN-A. Two of the four strains contained mannose, kut none of them had madurose. In having arabinose, galactose and LCN-A without madurose, these three aggregates $(N$. carnea, $N$. vaccinil, and $N$. transvalensis) chromatographically resembled strains of $N$. asteroides, $N$. amarae, $N$. caviae and $N$. brasiliensis.

Although our 21 strains of $N$. orientalis also contained arabinose and galactose but no madurose, hydrolysates of the 18 strains examined did not have LCN-A and thus resembled strains of $N$. autotrophica and $N$. hirsuta. The 14 strains of $N$. aerocolonigenes contained galactose and mannose; seven of the strains had glucose; four had madurose; and none had arabinose or LCN-A. In their lack of arabinose and LCN-A, the strains of N. aerocolonigenes resembled strains of $N$. dassonvillei, $N$. madurae and $N$. pelletieri. The presence of madurose in four of the 14 strains also indicated a relationship between $N$. aerocolonigenes and $N$. madurae and $N$. pelletieri. 


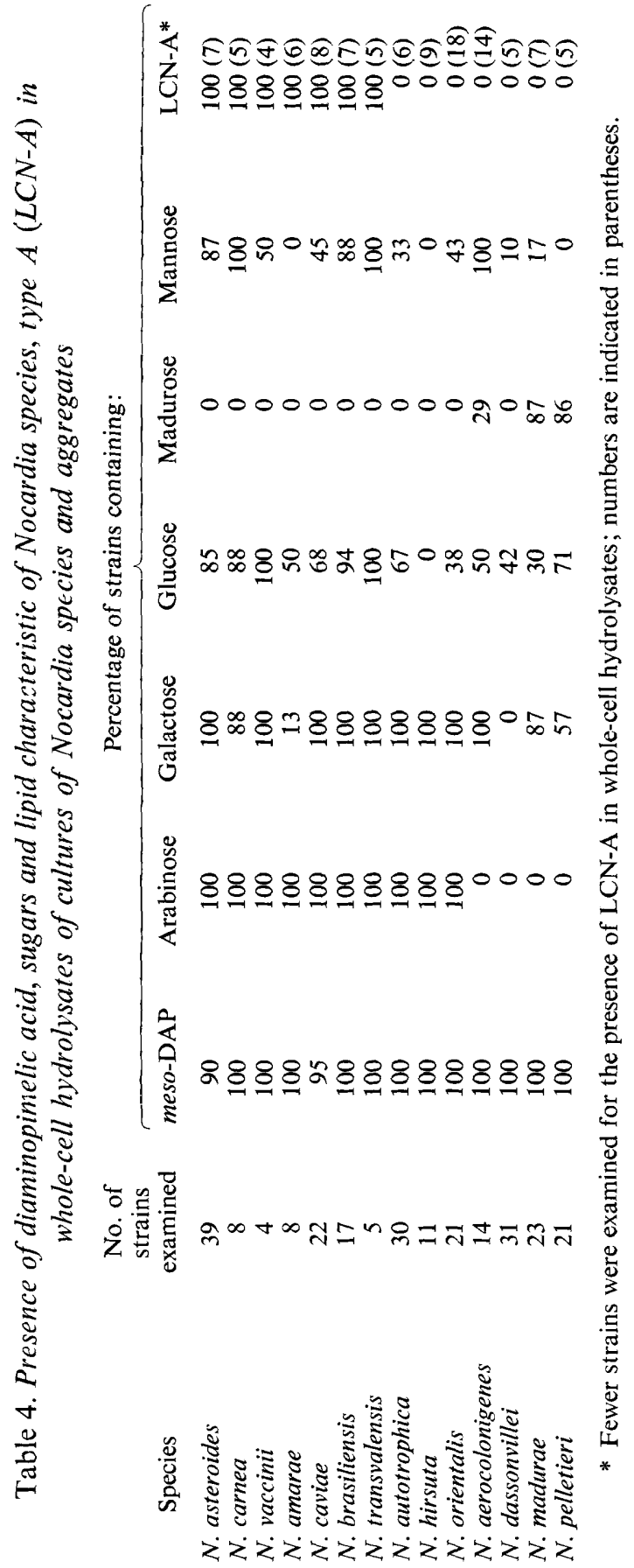




\section{DISCUSSION}

We have included all 14 taxa described here in the genus Nocardia because many of them are of medical importance and their generic and species identifications should not be beyond the capabilities of the routine diagnostic laboratory (Gordon, 1976). Among the 14 taxa Saccharopolyspora hirsuta Lacey \& Goodfellow 1975 is the only one not previously assigned to the genus Nocardia. Its assignment here is in confirmation of Lacey's (1974) designation of his isolations from bagasse as Nocardia spp.

The strains of $N$. vaccinii, $N$. transvalensis, $N$. orientalis and $N$. aerocolonigenes marked with an asterisk in Table 1 are generally accepted as the nomenclatural type strains of the respective taxa. However, the type strain of $N$. carnea has been lost and a neotype strain has not been designated. We propose, therefore, that ATCC 6847 (NCTC 3527), which has long been available, be accepted as the neotype strain of $N$. carnea.

The fore-mentioned physiological and biochemical characteristics of strains belonging to the five aggregates, i.e. $N$. carnea, $N$. vaccinii, $N$. transvalensis, $N$. orientalis and $N$. aerocolonigenes, differentiate them from the well known species, $N$. asteroides, $N$. caviae, $N$. brasiliensis, $N$. dassonvillei, $N$. madurae and $N$. pelletieri, and also from the lesser known $N$. amarae, $N$. autotrophica and $N$. hirsuta. However, only the availability of more strains from different sources and a detailed study of their properties will establish the status of the aggregates as distinct species.

As Tables 2 and 4 attest, within the limits of our methods, nearly every property of a species may vary, especially when a large number of strains are examined. Nor is microbial variation limited to species. Properties used for demarcation of genera may also vary. Tests for the presence of meso-DAP, suggested by Cummins \& Harris (1958) as having taxonomic value in describing the genus Nocardia and subsequently widely used, were negative for $10 \%$ of our strains of $N$. asteroides and for $5 \%$ of the strains of $N$. caviae (Table 4). Tests for the presence of madurose, used by Meyer (1976) in a generic separation of $N$. madurae and $N$. pelletieri from $N$. dassonvillei, were positive for $87 \%$ of our strains of $N$. madvrae, $86 \%$ of the strains of $N$. pelletieri and $29 \%$ of the strains of $N$. aerocolonigenes. The production of aerial hyphae, a characteristic used by Gordon (1976) to define the genus Nocardia, varied among the strains described here. Five strains of $N$. aerocolonigenes did not form aerial hyphae, although some, for example the type strain (ISP 5034), did when first isolated. Because the other properties (morphological, physiological and chemotaxonomic) of these strains without aerial hyphae were those of $N$. aerocolonigenes, we did not hesitate to accept them as strains of this species. Their similarities far outweighed their differences.

This investigation was supported in part by grants from the Charles and Johanna Busch Memorial Fund, the Schering-Plough Foundation and the Merck Company Foundation; we are very grateful for this assistance. We also wish to thank the many investigators who have given us their strains.

\section{REFERENCES}

Castellani, A. \& Chalmers, A. J. (1913). Manual of Tropical Diseases, 2nd edn. New York: William Wood \& Co.

Cummins, C. S. \& H.ARris, H. (1958). Studies on the cell-wall composition and taxonomy of actinomycetales and related groups. Journal of General Microbiology 18, 173-189.

Demaree, J. B. \& Smith, N. R. (1952). Nocardia vaccinii n.sp. causing galls on blueberry plants. Phytopathology 42, 249-252.

Gordon, R. E. (1976). A taxonomist's obligation. In The Biology of the Nocardiae, pp. 66-73. Edited by M. Goodfellow, G. H. Brownell and J.A. Serrano. London: Academic Press.

Gordon, R. E. \& Barnetr, D. A. (1977). Resistance to rifampin and lysozyme of strains of some species of Mycobacterium and Nocardia as a taxonomic tool. International Journal of Systematic Bacterio$\log y 27,176-178$.

Gordon, R. E., Barnett, D. A., Handerhan, J. E. \& PANG, C. H-N. (1974). Nocardia coeliaca, Nocardia autotrophica, and the nocardin strain. International Journal of Systematic Bacteriology 24, 54-63. 
Hecht, S. T. \& Causey, W. A. (1976). Rapid method for the detection and identification of mycolic acids in aerobic actinomycetes and related bacteria. Journal of Clinical Microbiology 4, 284-287.

LACEY, J. (1974). Moulding of sugar-cane bagasse and its prevention. Annals of Applied Biology 76, 63-76.

LACEY, J. \& Goodfellow, M. (1975). A novel actinomycete from sugar-cane bagasse: Saccharopolyspora hirsuta gen. et sp.nov. Journal of General Microbiology 88, 75-85.

Lechevalier, M. P. \& Lechevalier, H. A. (1974). Nocardia amarae sp.nov., an actinomycete common in foaming activated sludge. International Journal of Systematic Bacteriology 24, 278-288.

MEyer, J. (1976). Nocardiopsis, a new genus of the order Actinomycetales. International Journal of Systematic Bacteriology 26, 487-493.
PIJPer, A. \& Pullinger, B. D. (1927). South African nocardiases. Journal of Tropical Medicine and Hygiene 30, 153-156.

Pittenger, R. C. \& Brigham, R. B. (1956). Streptomyces orientalis, n.sp., the source of vancomycin. Antibiotics and Chemotherapy 6, 642-647.

Pridham, T. G. (1970). New Names and New Combinations in the Order Actinomycetales Buchanan 1917. United States Department of Agriculture, Technical Bulletin no. 1424.

Rossi-Doria, T. (1891). Su di alcune specie di 'Streptothrix' trovate nell'aria studiate in rapporto a quelle già note e specialmente all' 'Actinomyces.' Arinali dell' Istituto d'Igiene Sperimentale Università Roma 1, 399-438.

Shinobu, R. \& Kawato, M. (1960). On Streptomyces aerocolonigenes nov.sp., forming secondary colonies on the aerial mycelia. Botanical Magazine (Tokyo) 73, 212-216. 